\title{
Interaction of 1,1-Diamino-2,2-Dinitroethylene and Gallium - DFT Treatment
}

\section{Lemi Türker}

Department of Chemistry, Middle East Technical University, Üniversiteler, Eskişehir Yolu No: 1, 06800 Çankaya/Ankara, Turkey; e-mail: lturker@gmail.com; lturker@metu.edu.tr

\begin{abstract}
1,1-diamino-2,2-dinitroethylene, commonly known as FOX-7, is an insensitive pull-push type explosive of nitramine class. Aluminized FOX-7, depending on its Al content and multiplicity was found to be susceptible to decomposition. Gallium atom, a third group element below $\mathrm{Al}$, also has an open shell electronic configuration. The present study considers FOX-7+nGa composites (n:1-3) and within the constraints of density functional theory at the level of UB3LYP/6-311++G(d,p) it has been found that gallium atom does not initiate any bond rupture. However, certain distortions in bond lengths and angles occur which might have some effect on the ballistic properties of FOX-7. Certain geometrical, quantum chemical and energy values of the composites as well as some spectral properties are presented.
\end{abstract}

\section{Introduction}

1,1-diamino-2,2-dinitroethylene (DADE, DADNE) is an insensitive high explosive known as FOX-7 [1]. It was synthesized in 1998 by members of the Swedish Defense Research Agency (FOI) [2,3]. Many researchers have investigated its explosive potential thoroughly [4-18]. Nitration of 4,6-dihydroxy-2-methylpyrimidine and then hydrolysis constitutes an alternative route to FOX-7 [19].

It is a novel insensitive high-energy material possessing good thermal stability and low sensitivity. Moreover, it exhibits excellent application performance among the

Received: August 13, 2019; Accepted: September 22, 2019

Keywords and phrases: 1,1-diamino-2,2-dinitroethylene, FOX-7, gallium, DFT, explosive.

Copyright (C) 2019 Lemi Türker. This is an open access article distributed under the Creative Commons Attribution License, which permits unrestricted use, distribution, and reproduction in any medium, provided the original work is properly cited. 


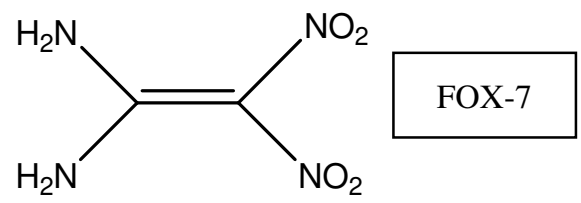

insensitive ammunitions and solid propellants. It has a simple molecular composition and structure, but it exhibits abundant chemical reactivity including coordination reactions, nucleophilic substitutions, acetylate reactions, oxidation and reduction reactions, electrophilic addition reactions etc., [20, 21]. FOX-7 is much less sensitive than RDX (in terms of impact, friction, and electrostatic discharge sensitivities) [22] although RDX or HMX possesses the same $\mathrm{C} / \mathrm{H} / \mathrm{N} / \mathrm{O}$ ratio as FOX-7 has. FOX-7 possesses many polymorphic forms of such as $\alpha$ - and $\beta$-forms. Of which the $\alpha$-form reversibly turns into $\beta$-form by heat treatment $[23,24]$. At higher temperature, an irreversible conversion of $\beta$-polymorph occurs to yield $\gamma$-phase which decomposes at $504 \mathrm{~K}$ [23] and its decomposition has been extensively searched [25]. The effect of high pressure on the crystal structure of FOX-7 has also been studied [26]. In the last couple of decades several FOX-7 based propellant formulations have been developed in order to obtain propellant composites having a minimum or reduced smoke production [27].

Recently, some novel derivatives of FOX-7 and their properties as energetic materials have been reported [28, 29]. Some aluminized FOX-7 compositions were reported [30, 31]. Also some molecular orbital calculations were reported on aluminized FOX-7 [32-36].

In the present study, interaction of 1,1-diamino-2,2-dinitroethylene and gallium (FOX-7+nGa (n:1-3)) have been investigated at the molecular level within the restriction of density functional theory (DFT).

\section{Method of Calculations}

Geometry optimizations of all the presently considered structures leading to energy minima were initially achieved by using MM2 method followed by semi-empirical PM3 self-consistent fields molecular orbital (SCF MO) method $[37,38]$ at the restricted level $[39,40]$. Subsequent optimizations were achieved at Hartree-Fock level using various basis sets. Then, the geometry optimizations were managed within the framework of density functional theory (DFT) using unrestricted B3LYP functional (UB3LYP) [41, 42] at the level of $6-311++G(d, p)$. The exchange term of B3LYP consists of hybrid 
Hartree-Fock and local spin density (LSD) exchange functions with Becke's gradient correlation to LSD exchange [42, 43]. Note that the correlation term of B3LYP consists of the Vosko, Wilk, Nusair (VWN3) local correlation functional [44] and Lee, Yang, Parr (LYP) correlation correction functional [45]. Presently, the vibrational analyses have been also done at the same level of calculations which had been performed for the optimizations. The total electronic energies (E) are corrected for the zero point vibrational energy (ZPE) to yield $\mathrm{E}_{\mathrm{c}}$ values. The normal mode analysis for each structure yielded no imaginary frequencies for the $3 N-6$ vibrational degrees of freedom, where $N$ is the number of atoms in the system. This indicates that the structure of each molecule corresponds to at least a local minimum on the potential energy surface. All these calculations were done by using the Spartan 06 package program [46].

\section{Results and Discussion}

Quite often some metals are employed with certain explosives to get better performance exhibiting ammunitions. Aluminum is one of them. However, a recent computational study has revealed that depending on the aluminum content and over all spin state of the composite, aluminized FOX-7, may undergo decomposition, while aluminum atom is oxidized and one of the N-O bonds of FOX-7 is broken [36].

In the present study, various gallium composites of FOX-7 are considered as analogous approach to its above mentioned aluminized composites. Gallium atom which is a third group element below the aluminum has $1 s^{2} 2 s^{2} 2 p^{6} 3 s^{2} 3 p^{6} 3 d^{10} 4 s^{2} 4 p^{1}$ electronic configuration in its ground state. The ionization potentials of the electrons of $\mathrm{Ga}$ atom in valency shell (n:4) are 30.6, 20.43 and $5.97 \mathrm{eV}$ for $4 \mathrm{~s}, 4 \mathrm{~s}$ and $4 \mathrm{p}$, respectively [47]. Whereas, the respective potentials for $\mathrm{Al}$ atom (3s, 3s and 3p) are 28.31, 18.74 and 5.96 $\mathrm{eV}$ [47]. The effective nuclear charge of $\mathrm{Ga}$ atom is greater than that of aluminum. Hence, the gallium atom shows smaller tendency to ionize than the aluminum atom [47]. All these information suggest that the presence of Ga should not cause any bond dissociation (maybe up to certain number of Ga atoms) of FOX-7 by transferring sufficient amount of electron density. However, it might cause deformation type perturbations on FOX-7 structure, thereby influencing its push-pull type behavior which might causes some changes on its ballistic properties. Below the influence of $\mathrm{Ga}$ on FOX-7 structure at the molecular level has been investigated. Note that depending on the number of $\mathrm{Ga}$ atoms, the composites have different multiplicities. 
Figure 1 shows the optimized structures of FOX-7 and its gallium composites from
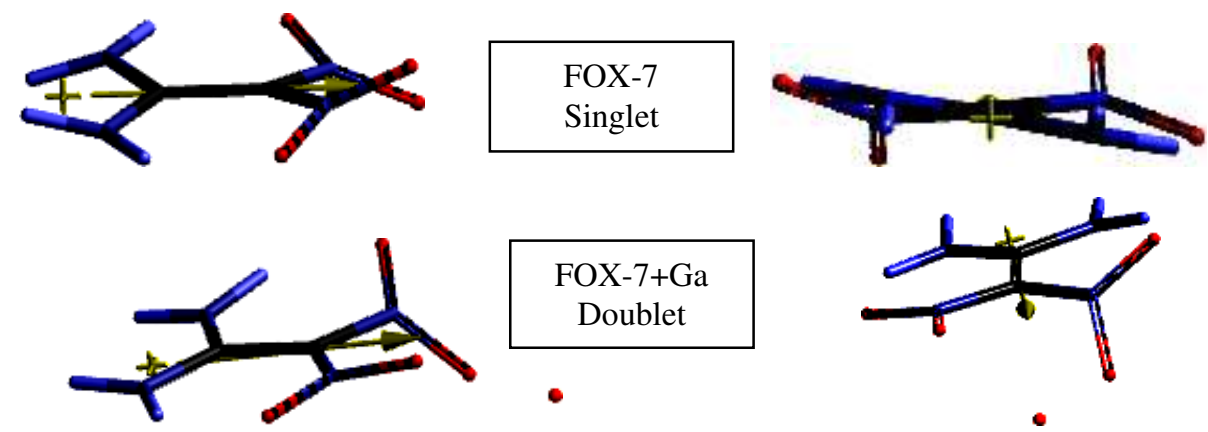

c
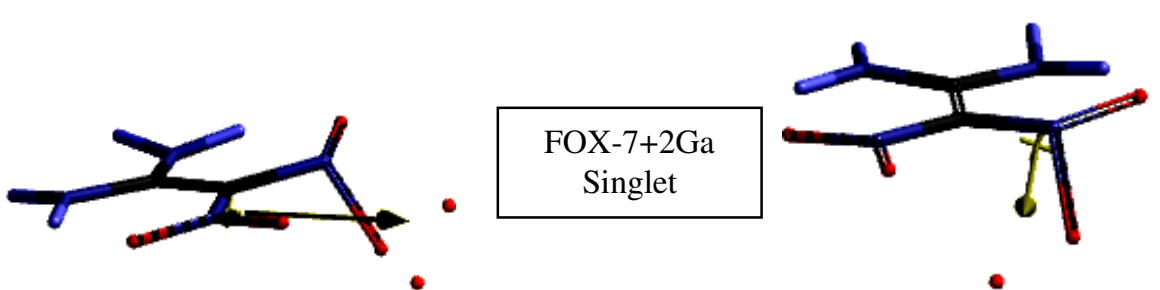

e
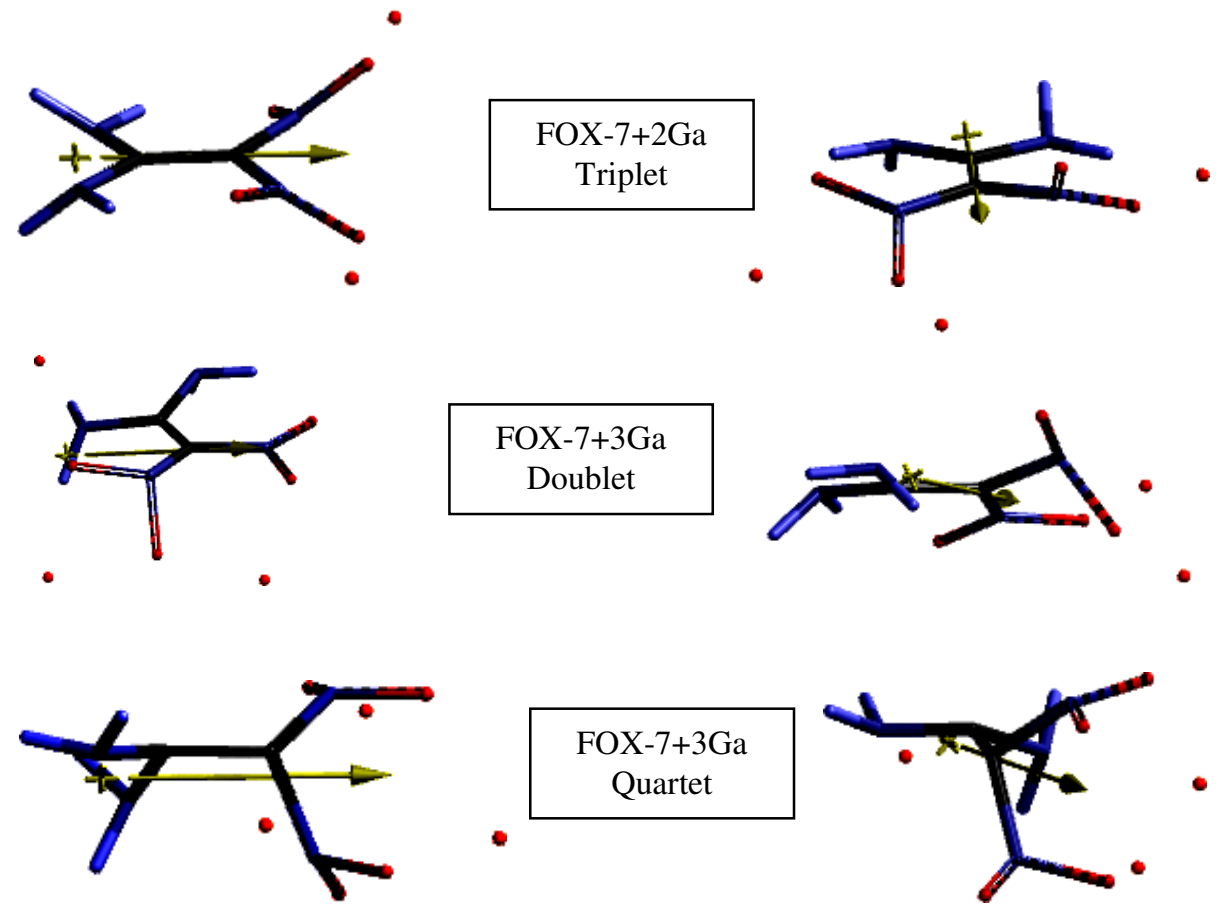

Figure 1. Optimized structures of FOX-7 and FOX-7+Ga composites from different angles of view. 
different angles of view. As seen in the figure, FOX-7 molecule is nearly planar. This geometry, together with two dimensional network of hydrogen bonds, contributes the pull-push character of the molecule and stability thus providing insensitiveness to the molecule. The electron donating ability of the amino groups in FOX-7 satisfies greatly the electron demand of the nitro groups, thus reducing their oxidative power. In the FOX-7+Ga composites, this nearly planar geometry is distorted bit by bit and in FOX$7+3 \mathrm{Ga}$ quartet the nitro groups became nearly perpendicular to the plane engendered by the amino groups and carbon atoms. That means that the composite should have lost its pull-push type character.

As seen in the figure some bond angles and dihedral angles concerning the amino as well as the nitro groups change as the number of Ga atoms vary. Figure 2 shows the bond lengths of FOX-7 and its gallium composites. The carbon-carbon bond lengths in the composites do not vary much (1-38-1.48 $\AA$ ), but N-O bond which is $1.48 \AA$ (in FOX-7 1.21-1.24 $\AA$ ) in singlet FOX-7+2Ga and $\mathrm{C}-\mathrm{NO}_{2}$ bond which is $1.52 \AA$ (in FOX-7 $1.43 \AA$ ) in quartet FOX-7+3Ga notably elongate.
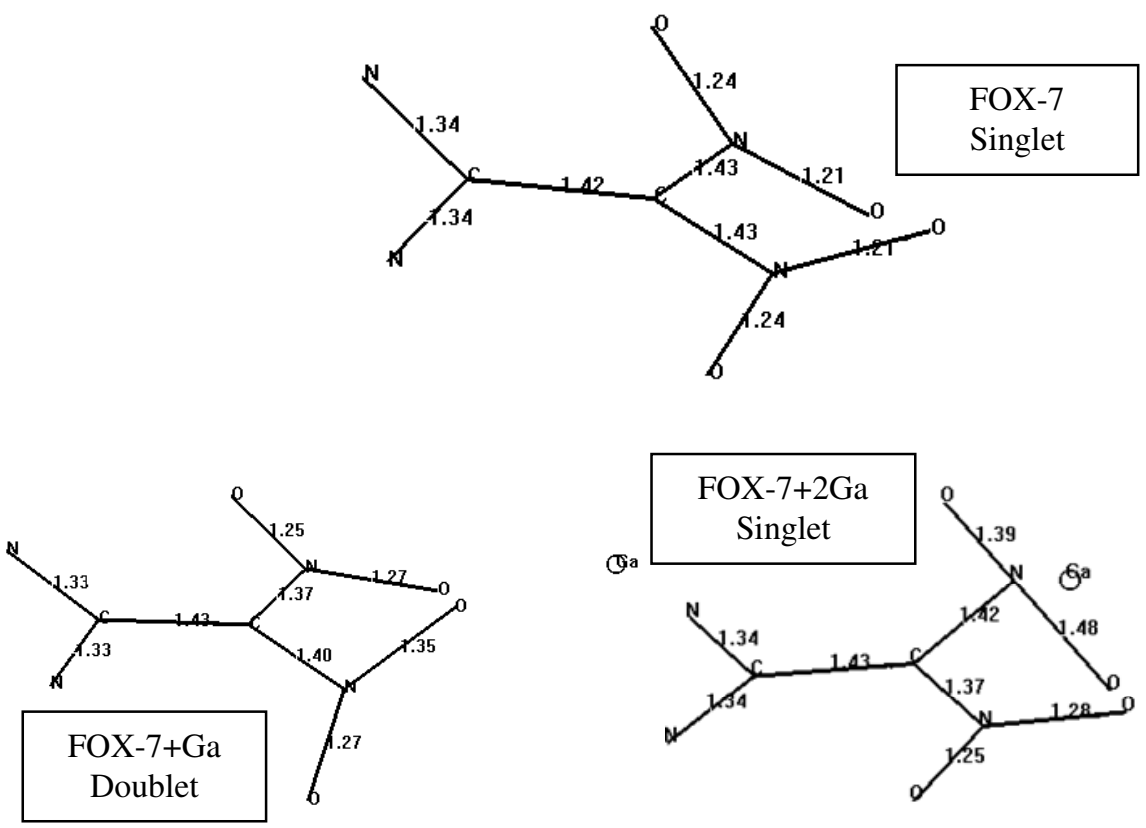

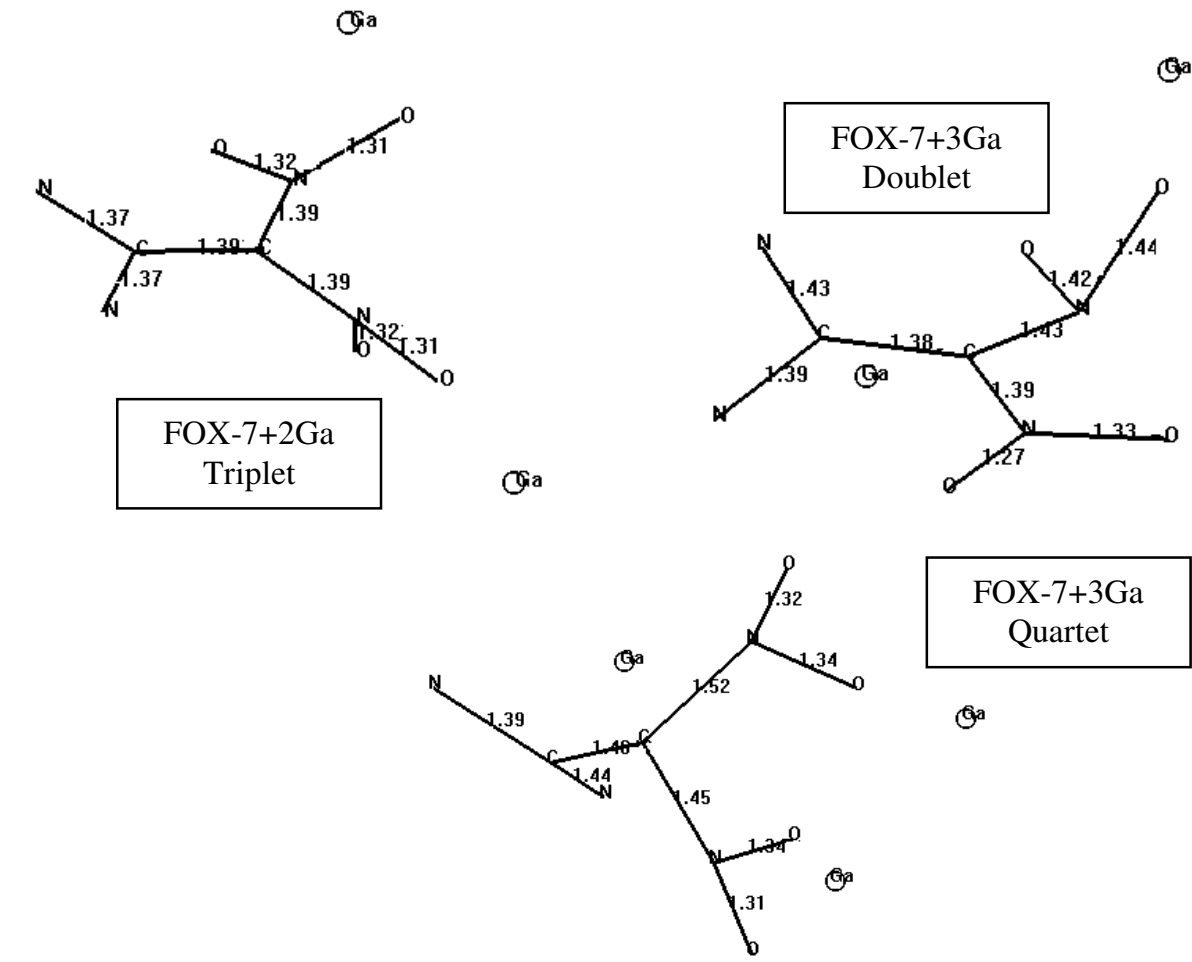

Ga

Figure 2. Bond lengths $(\AA)$ of FOX-7 and its gallium composites.

The presently calculated bond lengths of FOX-7 are in good accord with the literature data such that the reported length of the bond between carbon atoms in the molecule $(1.456 \AA)$ is intermediate between the length of a normal single bond (1.54 $\AA$ ) and a normal double bond (1.34 $\AA$ ). The lengths of the $\mathrm{C}-\mathrm{NO}_{2}$ bonds (1.42 and $1.39 \AA$ ) are close to the normal bond length of nitrogen-carbon with $\mathrm{sp}^{2}$ hybridization $(1.40 \AA$ ), but the $\mathrm{C}-\mathrm{NH}_{2}$ bonds (1.31 and $1.32 \AA$ ) are shorter by about $0.1 \AA$. The molecule has a generally planar structure $[10,48,49]$.

Figure 3 shows the IR spectra of FOX-7 and its gallium composites. FOX-7 possesses two N-H stretchings at $3469-3676 \mathrm{~cm}^{-1}$. Its $\mathrm{NH}_{2}$ scissoring vibrations occur at $1644 \mathrm{~cm}^{-1}$. The $\mathrm{C}=\mathrm{C}$ and $\mathrm{C}-\mathrm{N}$ stretchings happen in the region of $1568-1623 \mathrm{~cm}^{-1}$. FOX-7+Ga composite has three $\mathrm{N}-\mathrm{H}$ stretchings (asymmetric and symmetric) in the region of 3344-3667 $\mathrm{cm}^{-1}$. Whereas FOX-7+2Ga singlet has four but FOX-7+2Ga triplet just two N-H stretchings. Depending on the number and multiplicity of the composites IR spectra of them below $1500 \mathrm{~cm}^{-1}$ exhibit some peculiarities. 

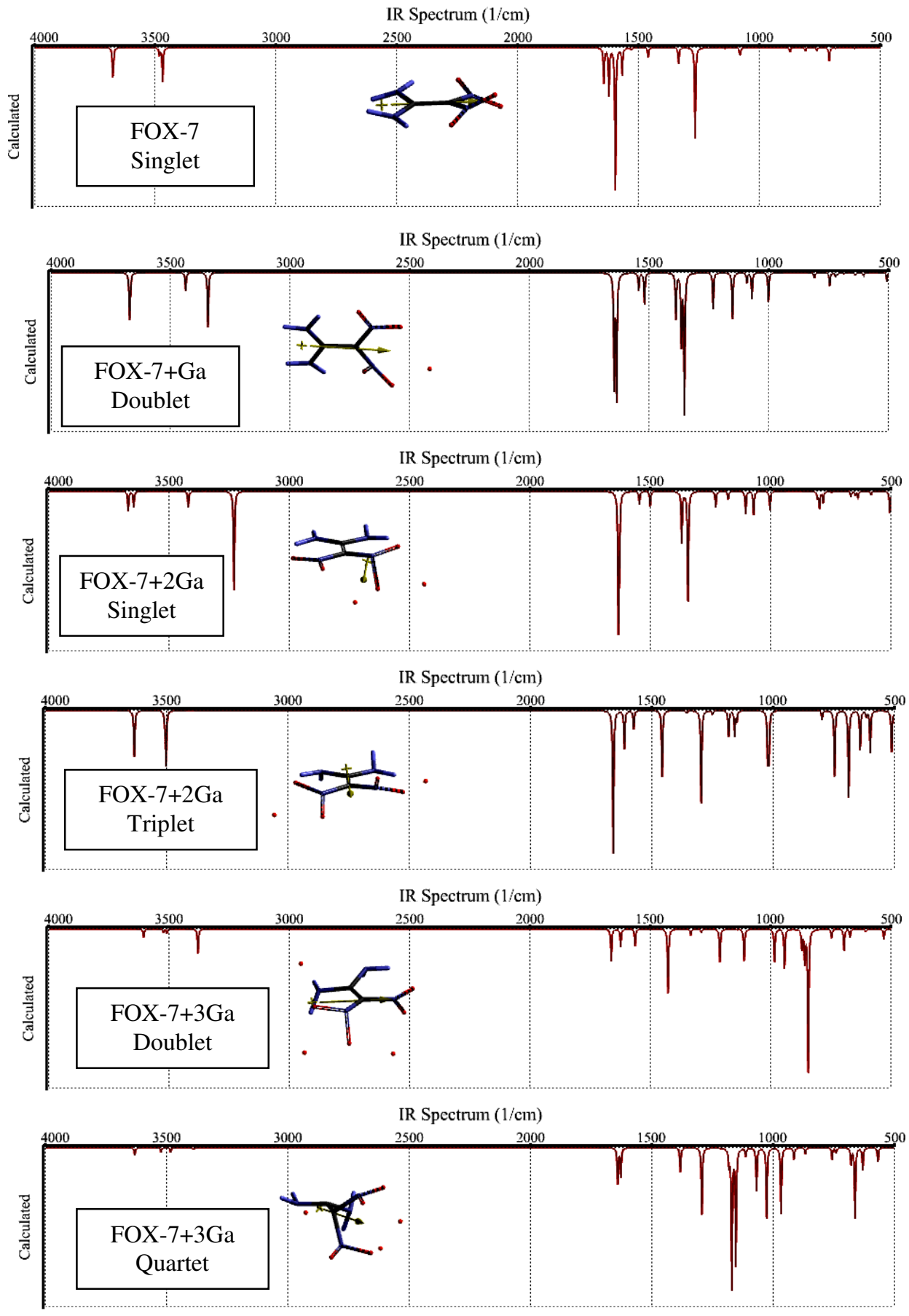

Figure 3. The calculated IR spectra of FOX-7 and its gallium composites. 
Table 1 tabulates some properties of the composites. The first column includes PM3//UB3LYP/6-311++G(d,p) values for the heat of formation values at the standard states in vacuum whereas the second column lists T1 results. The composite formation appears to be exothermic process in all the cases. T1 calculations involve more elaborate treatment. For FOX $-7+2 \mathrm{Ga}$ case the triplet state has less exothermic heat of formation value in both cases of the calculations. Whereas for FOX-7+3Ga composite the quartet is more exothermic than the doublet by PM3//UB3LYP/6-311++G(d,p) level of calculations in contrast to $\mathrm{T} 1$ calculations which yield results that the quartet happens to be less exothermic than the doublet.

Table 1. Some properties of the composites.

\begin{tabular}{lllllccc}
\hline Structure & $\begin{array}{l}\text { Heat of } \\
\text { formation* }\end{array}$ & $\begin{array}{l}\text { Heat of } \\
\text { formation** }\end{array}$ & $\begin{array}{c}\text { Area } \\
\left(\AA^{2}\right)\end{array}$ & $\begin{array}{l}\text { Volume } \\
\left(\AA^{3}\right)\end{array}$ & Ovality & $\begin{array}{c}\text { Dipole moment } \\
(\text { Debye })\end{array}$ & $\begin{array}{c}\text { MW } \\
(\mathrm{amu})\end{array}$ \\
\hline $\begin{array}{l}\text { FOX-7+Ga } \\
\text { Doublet }\end{array}$ & -107.552 & -4754520.42 & 162.97 & 134.30 & 1.28 & 6.60 & 217.80 \\
$\begin{array}{l}\text { FOX-7+2Ga } \\
\text { Singlet }\end{array}$ & -227.515 & -9509154.14 & 186.58 & 158.74 & 1.32 & 6.04 & 287.52 \\
$\begin{array}{l}\text { FOX-7+2Ga } \\
\text { Triplet }\end{array}$ & -193.662 & -9509024.15 & 195.76 & 161.81 & 1.36 & 2.92 & 287.52 \\
$\begin{array}{l}\text { FOX-7+3Ga } \\
\text { Doublet }\end{array}$ & -344.364 & -14263573.76 & 212.69 & 184.95 & 1.35 & 7.96 & 357.25 \\
$\begin{array}{l}\text { FOX-7+3Ga } \\
\text { Quartet }\end{array}$ & -582.205 & -14263121.28 & 202.77 & 182.90 & 1.30 & 4.76 & 357.25 \\
\hline
\end{tabular}

Heat of formation values in $\mathrm{kJ} / \mathrm{mol}$. *PM3// UB3LYP/6-311++G(d,p), **T1

As for the areas and volumes, as normally expected, they increase as the number of $\mathrm{Ga}$ atoms increase. However, the greater multiplicity state has greater values keeping the Ga content be the same but the quartet has smaller area and volume as compared to the doublet for FOX $-7+3 \mathrm{Ga}$ in the case of FOX $-7+3 \mathrm{Ga}$ composites. The ovality follows the same trend.

On the other hand, the order of dipole moments of the composites (FOX-7+nGa) is $3 \mathrm{Ga}(\mathrm{d})>\mathrm{Ga}(\mathrm{d})>2 \mathrm{Ga}(\mathrm{s})>3 \mathrm{Ga}(\mathrm{q})>2 \mathrm{Ga}(\mathrm{t})$ where the letter in parenthesis indicate the multiplicities.

Figures 4 and 5 show the ESP and natural charges on the atoms of the composites. Note that the ESP charges are obtained by the program based on a numerical method that generates charges that reproduce the electrostatic potential field from the entire wavefunction [46]. In both types of charge calculations $\mathrm{Ga}$ atom(s) acquire some positive charge less than unity, causing some distortions in the pull-push contributors, namely the amino and nitro groups. The carbon-carbon bond lengths do not vary appreciably (see Figure 2) but the others are affected which are accompanied by changes in bond and dihedral angles. In some of the composites considered, the groups are notably out of plane, e.g., quartet state of FOX-7+3Ga. 

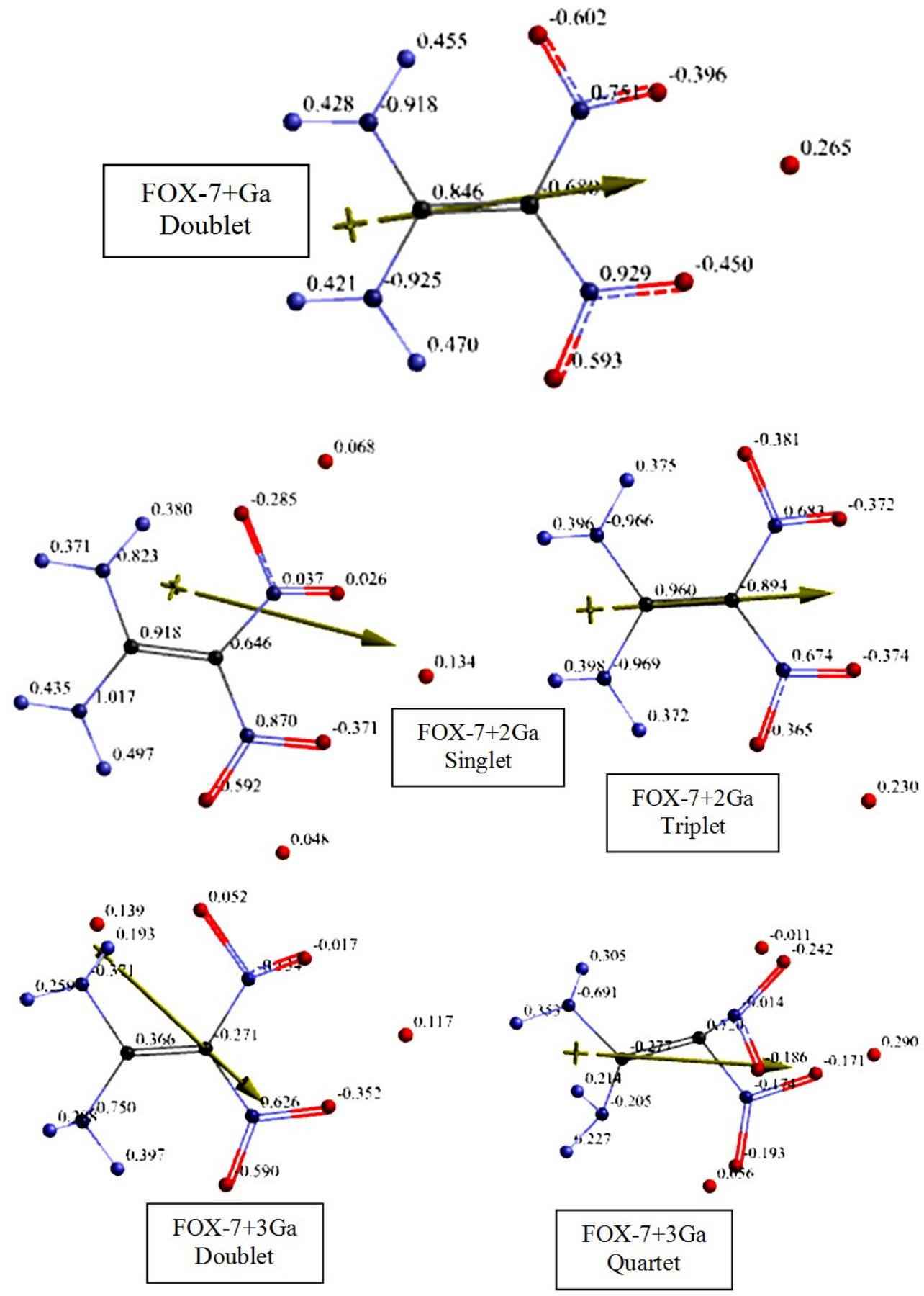

Figure 4. ESP charges on atoms of the composites. 


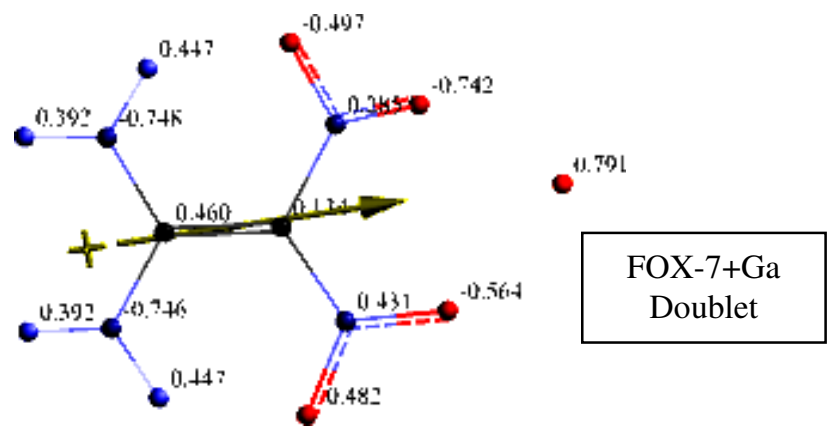

$e^{0.727}$
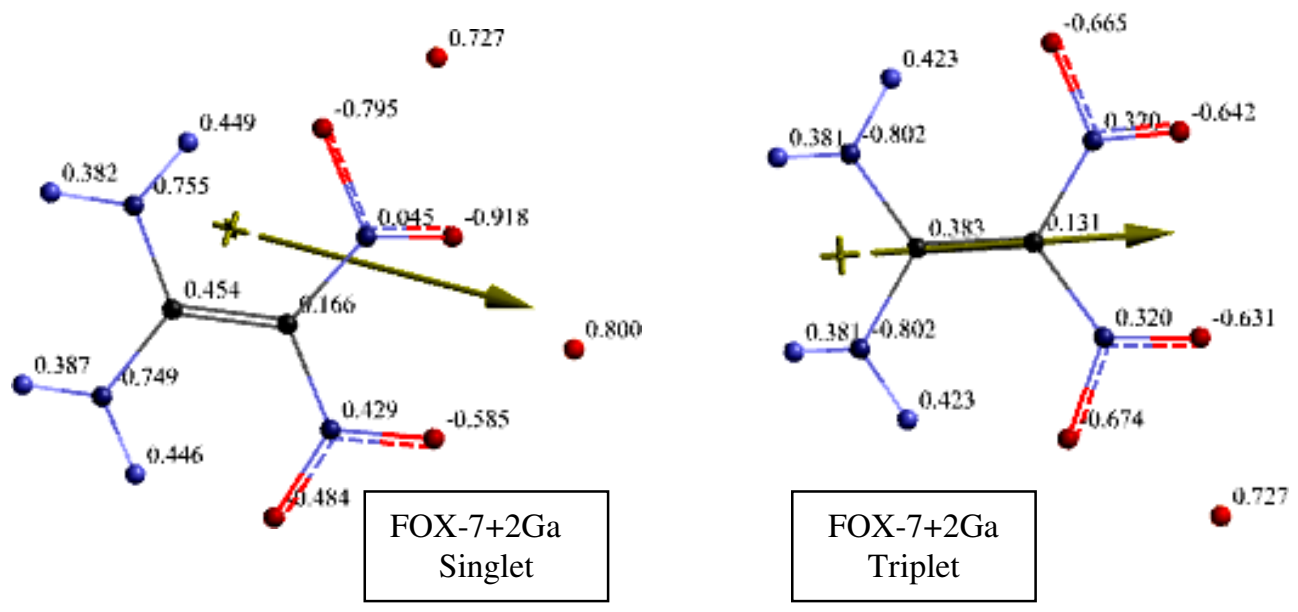

$e^{0.756}$
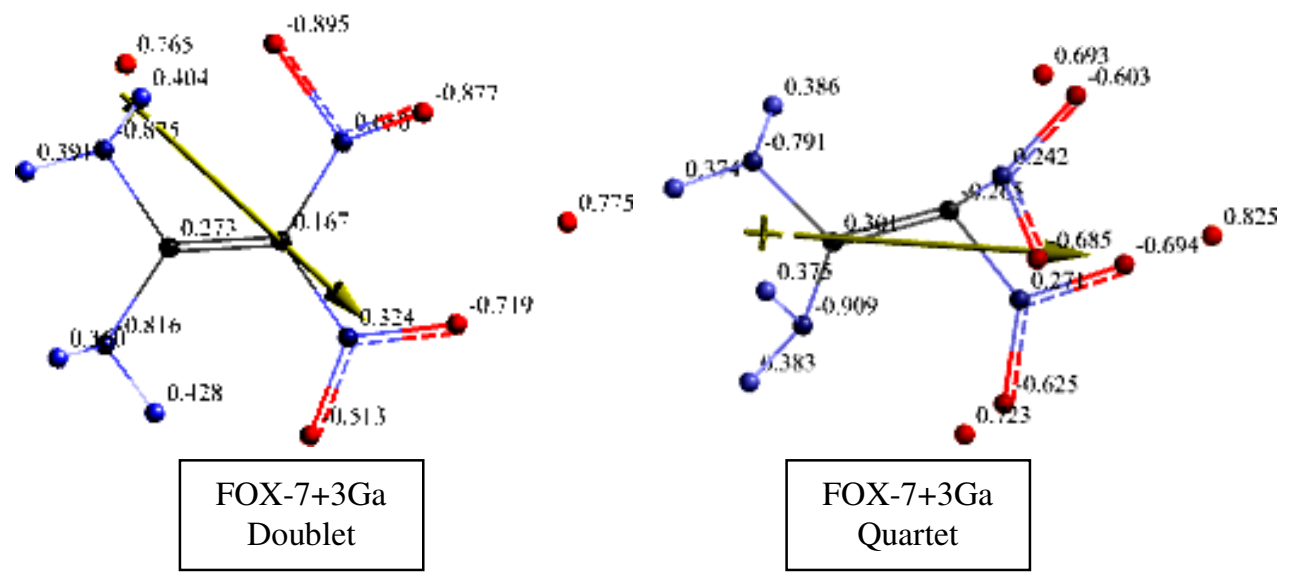

Figure 5. Natural charges on atoms of the composites. 
Table 2 shows various energies of the composites considered where E, ZPE and $\mathrm{E}_{\mathrm{c}}$ stand for the total electronic energy, zero-point vibrational energy and the corrected total electronic energy, respectively. As seen in the table, keeping the number of Ga atoms in each set, lower multiplicity having composite is more stable than the higher one based on $\mathrm{E}_{\mathrm{c}}$ values.

Table 2. Various energies of the composites.

\begin{tabular}{lccc}
\hline Structure & $\mathbf{E}$ & $\mathbf{Z P E}$ & $\mathbf{E}_{\mathbf{c}}$ \\
\hline FOX-7+Ga & -6625228.50 & 236.465330 & -6624992.035 \\
$\begin{array}{l}\text { Doublet } \\
\text { FOX-7+2Ga } \\
\text { Singlet }\end{array}$ & -11679113.0 & 237.189441 & -11678875.81 \\
$\begin{array}{l}\text { FOX-7+2Ga } \\
\text { Triplet }\end{array}$ & -11679017.4 & 235.419464 & -11678781.98 \\
$\begin{array}{l}\text { FOX-7+3Ga } \\
\text { Doublet }\end{array}$ & -16732845.5 & 236.923245 & -16732608.58 \\
$\begin{array}{l}\text { FOX-7+3Ga } \\
\text { Quartet }\end{array}$ & -16732666.4 & 232.273075 & -16732434.13 \\
\hline
\end{tabular}

Energies in $\mathrm{kJ} / \mathrm{mol}$.

Figure 6 shows some of the molecular orbital energy levels of the composites. Note that some of the composites have certain multiplicities which lead to open shell structures and then the unrestricted calculations yield $\alpha$ - and $\beta$-type orbitals (in the figure a- and b-types). In those cases $\alpha$-HOMO energy levels are higher than the respective $\beta$-type orbital energies. A similar situation happens for the LUMO energy levels with the exception of FOX-7+ Ga case. The HOMO and LUMO energy levels are collected in Table 3. It also includes $\Delta \varepsilon$ values which are the interfrontier energy gaps, namely $\varepsilon_{\mathrm{LUMO}}-\varepsilon_{\mathrm{HOMO}}$. The order of HOMO energy levels of FOX-7+nGa composites is $2 \mathrm{Ga}(\mathrm{s})<\mathrm{Ga}(\mathrm{d})<3 \mathrm{Ga}(\mathrm{q})<2 \mathrm{Ga}(\mathrm{t})<3 \mathrm{Ga}(\mathrm{d})$. Whereas the LUMO energy levels follow the order of $\mathrm{Ga}(\mathrm{d})<2 \mathrm{Ga}(\mathrm{s})<3 \mathrm{Ga}(\mathrm{d})<2 \mathrm{Ga}(\mathrm{t})<3 \mathrm{Ga}(\mathrm{q})$. Consequently, the order of $\Delta \varepsilon$ values happens as $3 \mathrm{Ga}(\mathrm{q})>2 \mathrm{Ga}(\mathrm{s})>2 \mathrm{Ga}(\mathrm{t})>\mathrm{Ga}(\mathrm{d})>3 \mathrm{Ga}(\mathrm{d})$. Note that $\Delta \varepsilon$ values in the table are constituted in between the smallest possible difference of the HOMO and LUMO energies corresponding to $\alpha$ - and/or $\beta$-type orbitals. 

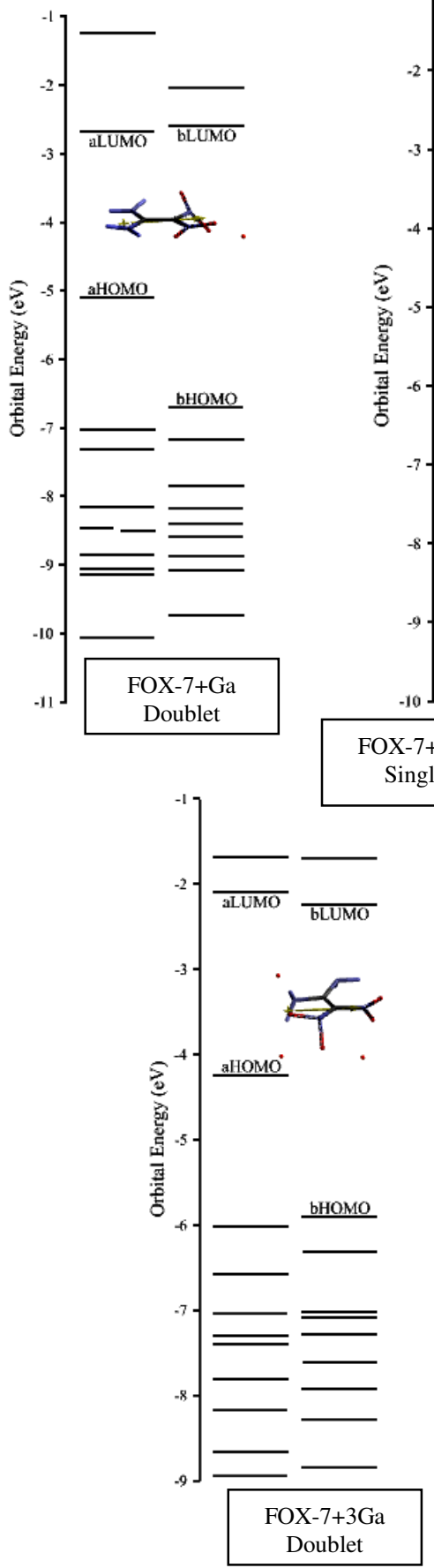
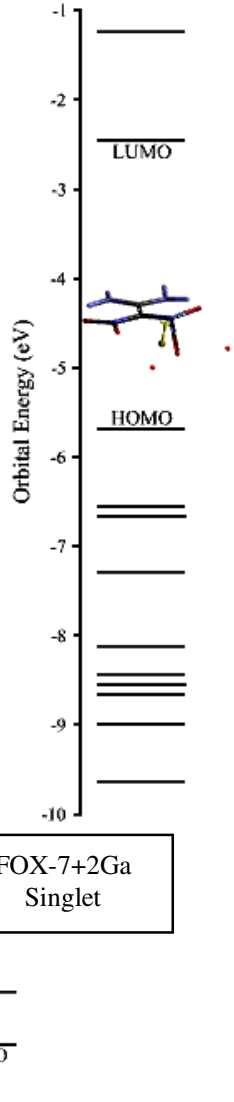

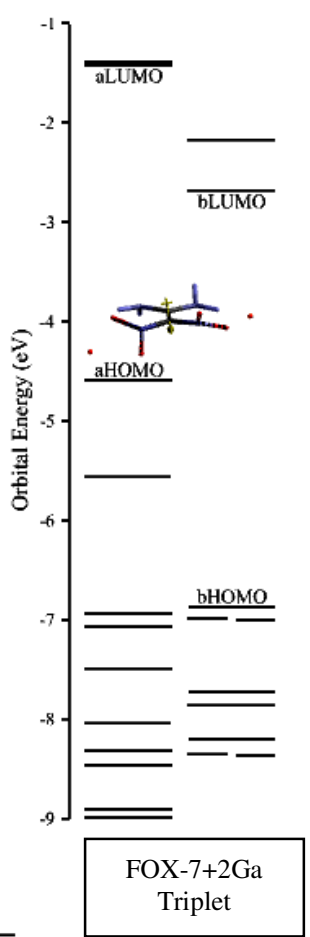

$\overline{\overline{\text { aLUMO }}}$
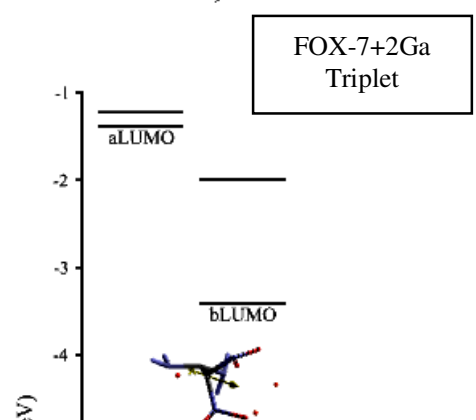

离

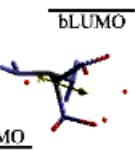

-5
-6
-7
-8
-9
-10

-

=
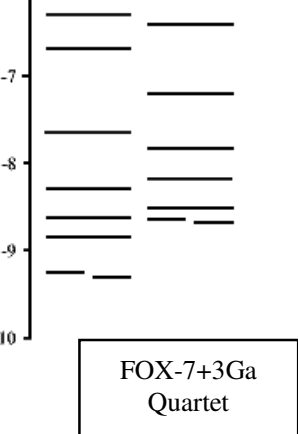

Figure 6. Some of the molecular orbital energy levels of the composites. 
Table 3. Some molecular orbital energies of the composites.

\begin{tabular}{lccc}
\hline Structure & HOMO & LUMO & $\Delta \varepsilon$ \\
\hline FOX-7+Ga & -492.561583 & -258.310027 & 234.2516 \\
$\begin{array}{l}\text { Doublet } \\
\text { FOX-7+2Ga }\end{array}$ & -547.982115 & -237.037986 & 310.9441 \\
$\begin{array}{l}\text { Singlet } \\
\text { FOX-7+2Ga }\end{array}$ & -443.015922 & -136.783885 & 306.232 \\
Triplet & -409.494317 & -202.589026 & 206.9053 \\
$\begin{array}{l}\text { FOX-7+3Ga } \\
\text { Doublet }\end{array}$ & -480.136021 & -133.599811 & 346.5362 \\
$\begin{array}{l}\text { FOX-7+3Ga } \\
\text { Quartet }\end{array}$ & & & \\
\hline
\end{tabular}

Energies in $\mathrm{kJ} / \mathrm{mol}$.

The time-dependent UV-VIS spectra (TDDFT) of the composites are shown in Figure 7. As seen in the figure, FOX $-7+2 \mathrm{Ga}$ singlet and FOX $-7+3 \mathrm{Ga}$ doublet absorptions should occur in the visible region whereas the others occur in the UV-VIS range of the spectrum.
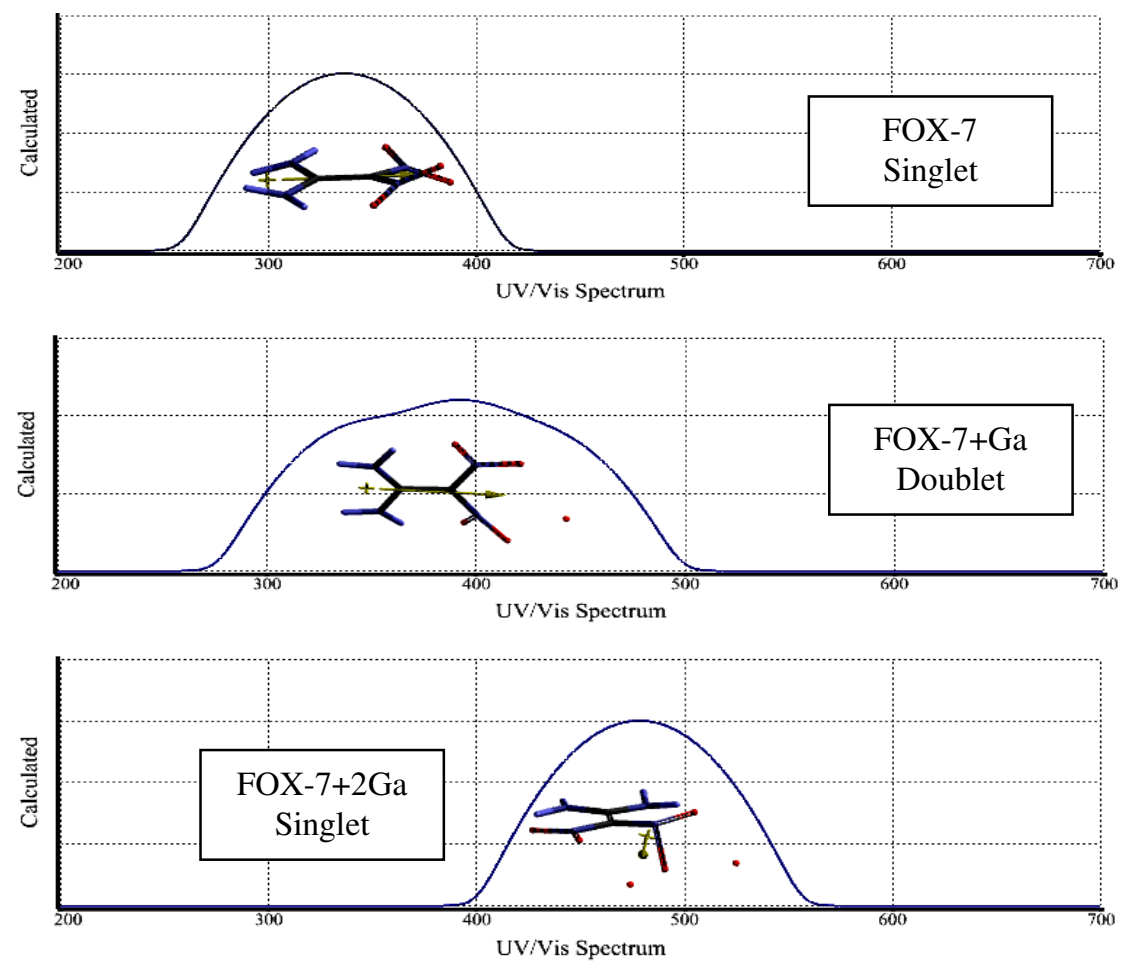

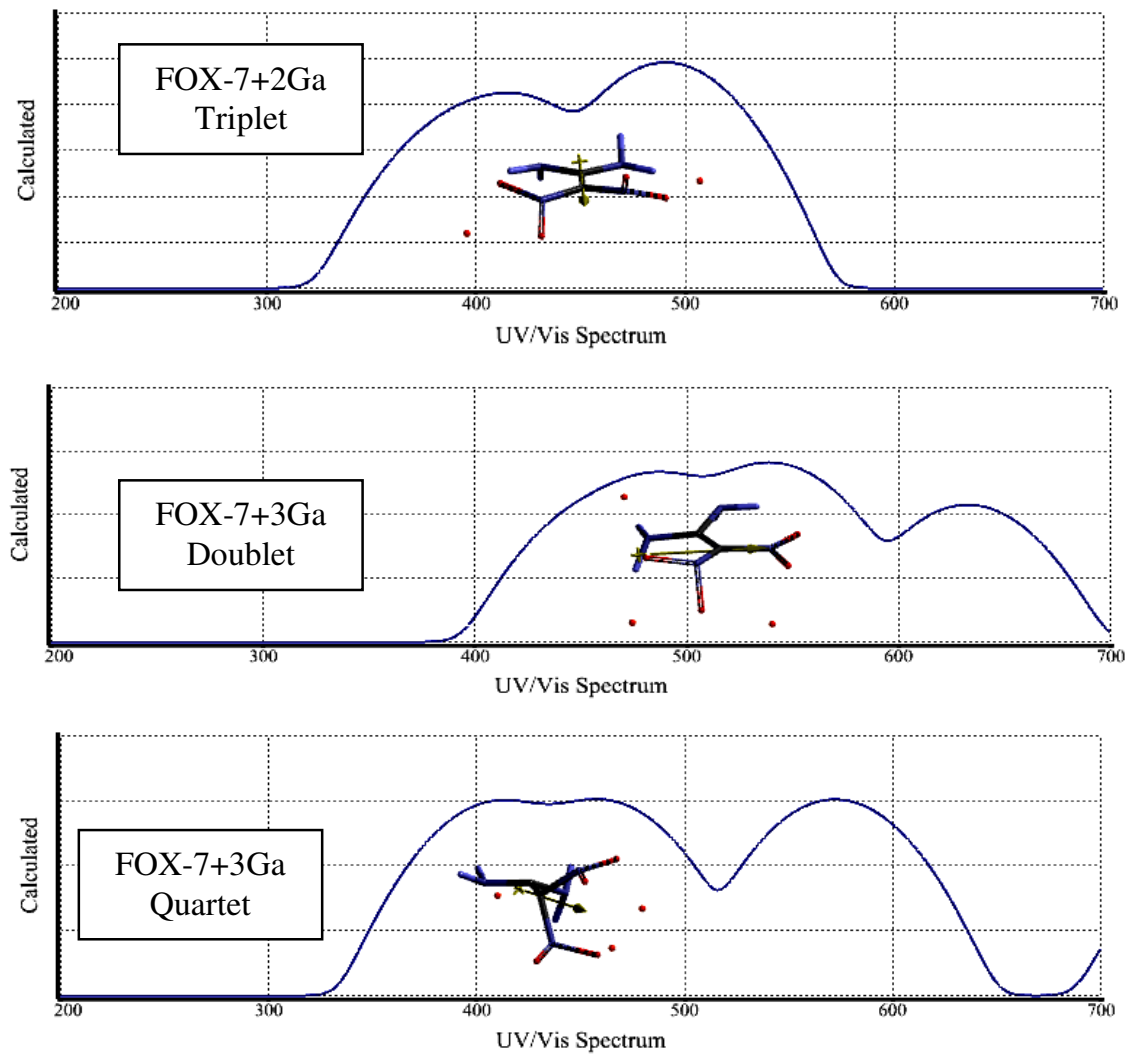

Figure 7. UV-VIS spectra of FOX-7 and its gallium composites.

Figure 8 shows the effect of gallium atoms on the HOMO and LUMO patterns of the composites.

FOX-7+Ga

Doublet

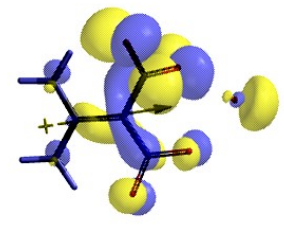

$\alpha \mathrm{HOMO}$

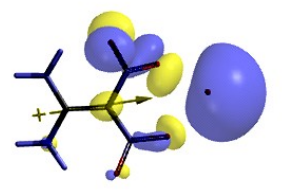

BHOMO

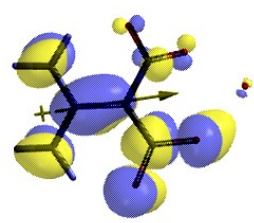

$\alpha$ LUMO

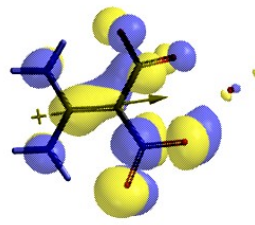

$\beta$ LUMO 

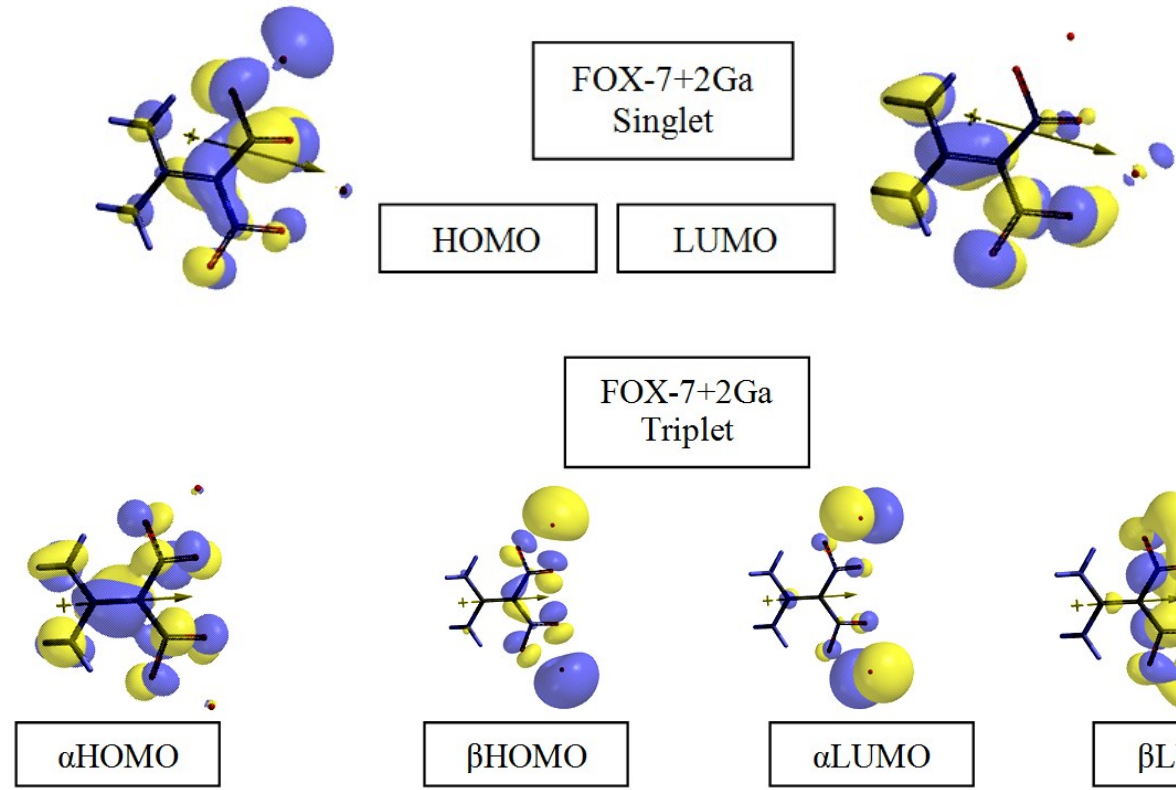

Triplet
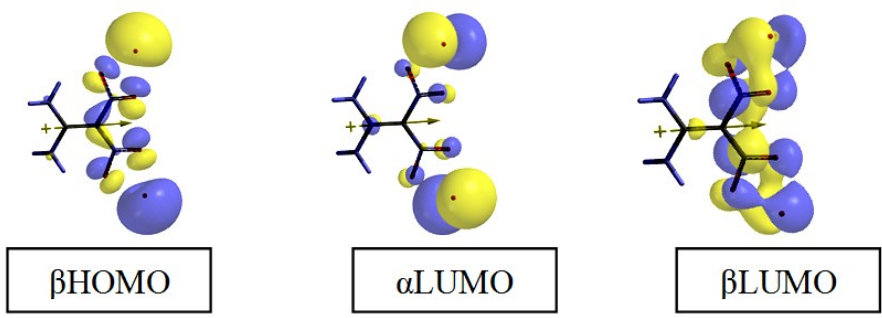

\section{FOX-7+3Ga}

Doublet
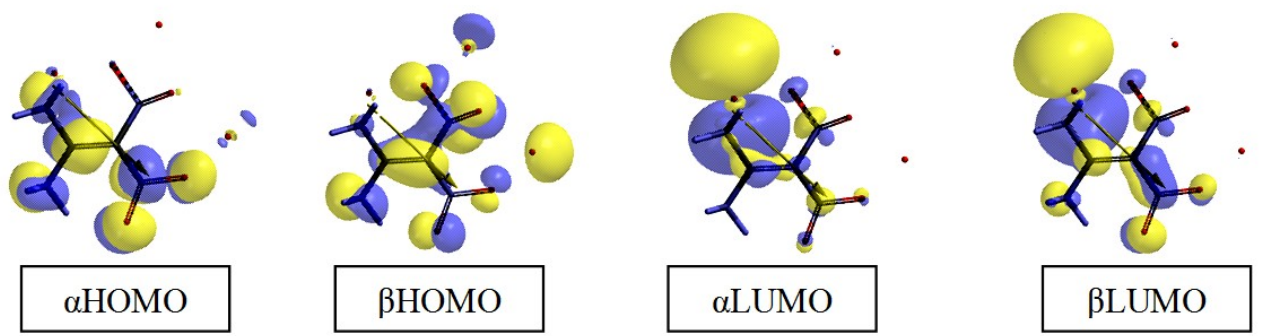

\section{FOX-7+3Ga}

Quartet
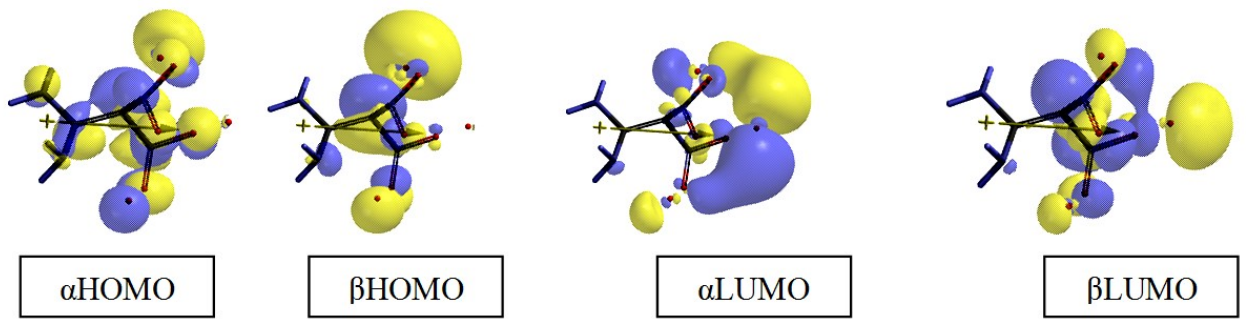

Figure 8. The HOMO and LUMO patterns of the composites. 
Figure 9 shows the electrostatic potential maps of the composites. Note that in the figure red and blue regions stand for electronegative and electropositive potential regions, respectively. As seen in the figure, $\mathrm{Ga}$ atom(s) perturbs electrostatic potential field around FOX-7 although no bond ruptures occur.
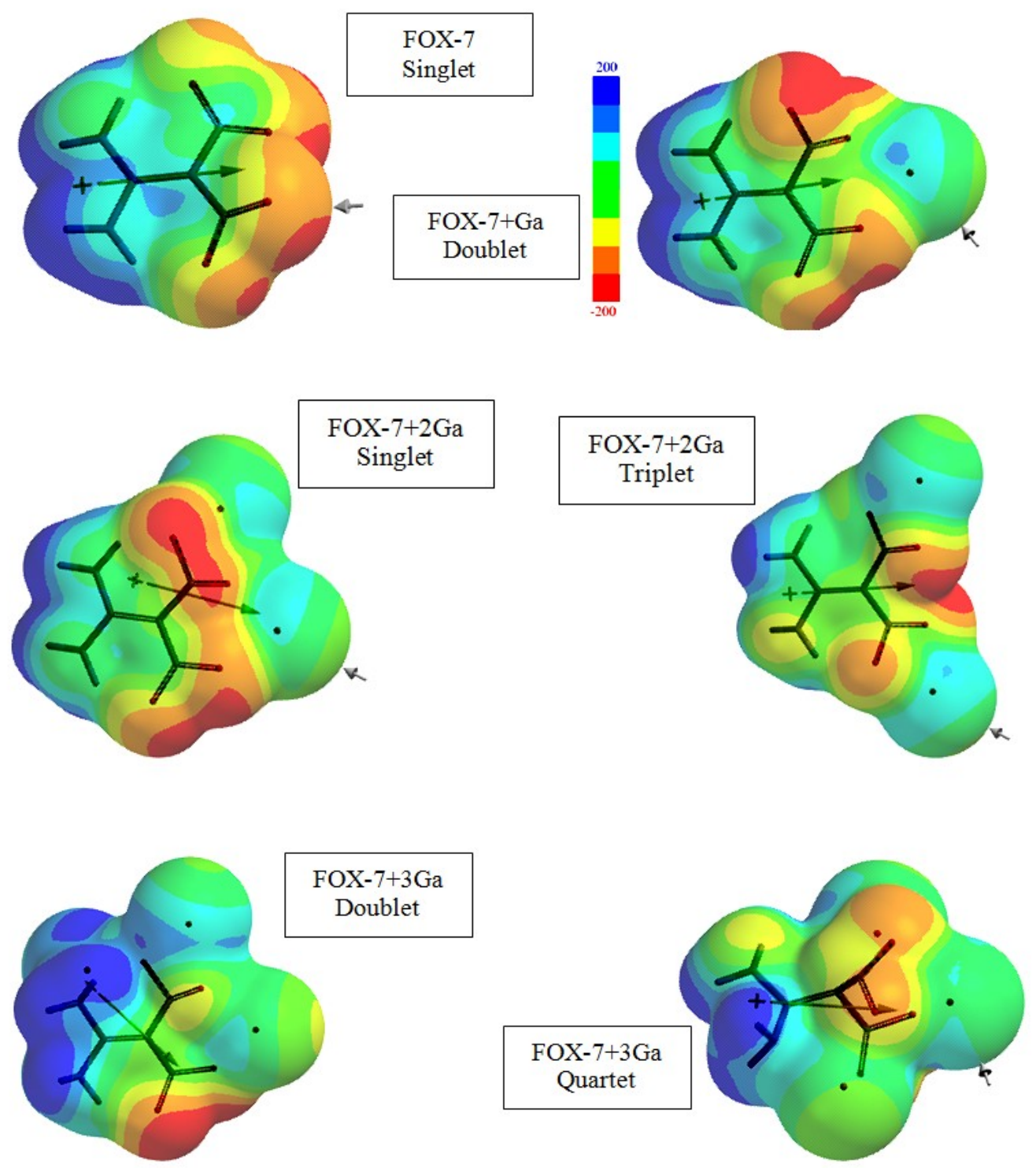

Figure 9. Electrostatic potential maps of FOX-7 and its gallium composites. 


\section{Conclusion}

Within the restrictions of the density functional theory at the applied level, it has been found that FOX-7+nGa (n:1-3) composites are exothermic and electronically stable no matter the multiplicities of the composites are. However, certain bond length and angle distortions occur which affect certain geometrical, quantum chemical and energetic properties of FOX-7. All those perturbations probably affect ballistic properties of the explosive.

\section{References}

[1] J. P. Agrawal, High Energy Materials, Weinheim: Wiley-VCH, 2010. https://doi.org/10.1002/9783527628803

[2] P. Politzer and J. S. Murray, Energetic Materials, Part 1, Amsterdam: Elsevier, 2003.

[3] I. J. Lochert, FOX-7 - A new insensitive explosive FOX-7, DSTO Aeronautical and Maritime Research Laboratory 506 Lorimer St, Fishermans Bend, Victoria 3207, Australia 2001, AR-012-065, November 2001.

[4] N. V. Latypov, J. Bergman, A. Langlet, U. Wellmar and U. Bemm, Synthesis and reactions of 1,1-diamino-2,2-dinitroethylene, Tetrahedron 54 (1998), 11525-11536. https://doi.org/10.1016/S0040-4020(98)00673-5

[5] U. Bemm and H. Östmark, 1,1-diamino-2,2-dinitroethylene: a novel energetic material with infinite layers in two dimensions, Acta Cryst. C54 (1998), 1997-1999. https://doi.org/10.1107/S0108270198007987

[6] N. V. Latypov, A. Langlet and U. Wellmar, New chemical compound suitable for use as an explosive, intermediate and method for preparing the compound, Patent WO99/03818, 1999.

[7] H. Östmark, H. Bergman, U. Bemm, P. Goede, E. Holmgren, M. Johansson, A. Langlet, N. V. Latypov, A. Petterson, M. L. Petterson, N. Wingborg, C. Vörde, H. Stenmark, L. Karlsson and M. Hihkiö, 2,2-Dinitro-ethene-1,1-diamine (FOX-7) - Properties, analysis and scale-up, 32nd International Annual Conference of ICT on Energetic MaterialsIgnition, Combustion and Detonation, Karlsruhe, Germany, 2001.

[8] H. Östmark, A. Langlet, H. Bergman, N. Wingborg, U. Wellmar and U. Bemm, FOX-7 A new explosive with low sensitivity and high performance, The 11th International Detonation Symposium, Colorado, USA, 1998. 
[9] H. Bergman, H. Ostmark, A. Pettersson, M. L. Petterson, U. Bemm and M. Hihkio, Some Initial properties and thermal stability of FOX-7, Insensitive Munitions and Energetic Materials Symposium (NDIA), Tampa, Florida, USA, 1999.

[10] W. A. Trzciński and A. Belaada, 1,1-Diamino-2,2-dinitroethene (DADNE, FOX-7) Properties and formulations (a review), Central European Journal of Energetic Materials 13(2) (2016), 527-544. https://doi.org/10.22211/cejem/65000

[11] B. Janzon, H. Bergman, C. Eldsater, C. Lamnevik and H. Ostmark, FOX-7 - A novel, high performance, low vulnerability high explosive for warhead applications, 20th Int. Symp. Ballistics. Orlando, Florida, USA: September 23-27, 2002.

[12] Y. N. Matyushin, G. T. Afanas'ev, V. P. Lebedev, M. N. Mahov and V. I. Pepekin, TATB and FOX-7: Thermochemistry, performance, detonability, sensitivity, 34th Int. Annu. Conf. ICT, Karlsruhe, Germany: June 24-27, 2003.

[13] A. J. Bellamy, N. V. Latypov and P. Goede, Studies on the nitration of new potential precursors for FOX-7, New Trends Res. Energ. Mater. Proc. Semin. 7th, Pardubice, Czech Republic: April 20-22, 2004.

[14] S. Cudziło, Z. Chyłek and R. Diduszko, Crystallization and characterization of 1,1diamino-2,2-dinitroethene (DADNE), 36th Int. Annu. Conf. ICT, Karlsruhe, Germany, June 28-July 1, 2005.

[15] W. A. Trzciński, S. Cudziło, Z. Chyłek and L. Szymańczyk, Investigation of sensitivity and detonation properties of FOX-7, 37th Int. Annu. Conf. ICT, Karlsruhe, Germany: June 27-30, 2006.

[16] M. Anniyappan, M. B. Talawar, G. M. Gore, S. Venugopalan and B. R. Gandhe, Synthesis, characterization and thermolysis of 1,1-diamino-2,2-dinitroethylene (FOX-7) and its salts, J. Hazard. Mater. B 137 (2006), 812-819.

https://doi.org/10.1016/j.jhazmat.2006.03.034

[17] W. A. Trzciński, S. Cudziło, Z. Chyłek and L. Szymańczyk, Detonation properties of 1,1diamino-2,2-dinitroethene (DADNE), J. Hazard. Mater. 157 (2008), 605-612. https://doi.org/10.1016/j.jhazmat.2008.01.026

[18] V. S. Mishra, S. R. Vadali, R. K. Garg, V. S. Joshi, R. D. Wasnik and S. Asthana, Studies on FOX-7 based melt cast high explosive formulations, Cent. Eur. J. Energ. Mater. 10(4) (2013), 569-580.

[19] N. V. Latypov, M. Johansson, E. Holmgren, E. V. Sizova, V. V. Sizov and A. J. Bellamy, On the synthesis of 1,1-diamino-2,2-dinitroethene (FOX-7) by nitration of 4,6-dihydroxy2-methylpyrimidine, Org. Process Res. Dev. 11(1) (2007), 56-59.

https://doi.org/10.1021/op068010t 
[20] Y. Zhang, Q. Sun, K. Xu, J. Song and F. Zhao, Review on the reactivity of 1,1-diamino2,2-dinitroethylene (FOX-7), Propellants Explos. Pyrotech. 41 (2016), 35-52. https://doi.org/10.1002/prep.201500065

[21] K. Baum, N. V. Nguyen, R. Gilardi, J. L. Flippen-Anderson and C. George, Nitration of 1,1-diamino-2,2-dinitroethylenes, J. Org. Chem. 57 (1992), 3026-3030. https://doi.org/10.1021/jo00037a015

[22] T. M. Klapötke, Chemistry of High-Energy Materials, Berlin: De Gruyter, 2011. https://doi.org/10.1515/9783110227840

[23] J. Evers, T. M. Klapötke, P. Mayer, G. Oehlinger and J. Welch, $\alpha-$ and $\beta-F O X-7$, polymorphs of a high energy density material, studied by X-ray single crystal and powder investigations in the temperature range from 200 to 423 K, Inorg. Chem. 45 (2006), 49965007. https://doi.org/10.1021/ic052150m

[24] M. J. Crawford, J. Evers, M. Göbel, T. M. Klapötke, P. Mayer, G. Oehlinger and J. M. Welch, $\gamma$-FOX-7: Structure of a high energy density material immediately prior to decomposition, Propellants Explos. Pyrotech. 32 (2007), 478-495. https://doi.org/10.1002/prep.200700240

[25] A. Gindulytè, L. Massa, L. Huang and J. Karle, Proposed mechanism of 1,1-diaminodinitroethylene decomposition: a density functional theory study, J. Phys. Chem. A 103 (1999), 11045-11051. https://doi.org/10.1021/jp991794a

[26] Z. A. Dreger, A. I. Stash, Z. G. Yu, Y. S. Chen, Y. Tao and Y. M. Gupta, High-pressure crystal structures of an insensitive energetic crystal: 1,1-diamino-2,2-dinitroethene, $J$. Phys. Chem. C 120(2) (2016), 1218-1224. https://doi.org/10.1021/acs.jpcc.5b10644

[27] H. Lips and K. Menke, FOX-7/GAP rocket propellants for a shoulder launched projectile. 27th International Symposium on Ballistics, Freiburg, Germany: April 22-26, 2013.

[28] T. Zhou, Y. Li, K. Xu, J. Song and F. Zhao, The new role of 1,1-diamino-2,2dinitroethylene (FOX-7): two unexpected reactions, New J. Chem. 41 (2017), 168-176. https://doi.org/10.1039/C6NJ03370A

[29] H. Gao and J. M. Shreeve, Recent progress in taming FOX-7 (1,1-diamino-2,2dinitroethene), RSC Adv. 6 (2016), 56271-56277. https://doi.org/10.1039/C6RA12412G

[30] J. Zhao, X. J. Feng, H. T. Xu, X. Tian and B. Feng, Shock initiation characteristics of FOX-7 and RDX based aluminized explosive, Huozhayao Xuebao/Chinese Journal of Explosives and Propellants 39(4) (2016), 42-45 and 50. 
[31] D. B. Lempert, E. M. Dorofeenko and Y. Shu, Energy potential of solid composite propellants based on 1,1-diamino-2,2-dinitroethylene, Russian Journal of Physical Chemistry B 10(3) (2016), 483-489. https://doi.org/10.1134/S1990793116030258

[32] C.-C. Ye, F.-Q. Zhao, S.-Y. Xu and X.-H. Ju, Density functional theory studies on adsorption and decomposition mechanism of FOX-7 on $\mathrm{Al}_{13}$ clusters, Canadian Journal of Chemistry 91(12) (2013), 1207-1212. https://doi.org/10.1139/cjc-2013-0334

[33] L. Bian, Y. Shu, J. Xu and L. Wang, Computational investigation on the new high energy density material of aluminum enriched 1,1-diamino-2,2-dinitroethylene, Journal of Molecular Modeling 19(1) (2013), 131-138. https://doi.org/10.1007/s00894-012-1533-x

[34] C. Ye, X. Ju, F. Zhao and S. Xu, Adsorption and decomposition mechanism of 1,1diamino-2,2-dinitroethylene on $\mathrm{Al}(111)$ surface by periodic DFT calculations, Chin. J. Chem. 30(10) (2012), 2539-2548. https://doi.org/10.1002/cjoc.201200470

[35] D. C. Sorescu, J. A. Boatz and D. L. Thompson, First-principles calculations of the adsorption of nitromethane and 1,1-diamino-2,2-dinitroethylene (FOX-7) molecules on the Al(111) surface, J. Phys. Chem. B 107(34) (2003), 8953-8964.

https://doi.org/10.1021/jp030258m

[36] L. Türker, Effect of aluminum on FOX-7 structure, Chinese Journal of Explosives and Propellants 42(3) (2019), 213-223.

[37] J. J. P. Stewart, Optimization of parameters for semiempirical methods I. Method, J. Comput. Chem. 10 (1989), 209-220. https://doi.org/10.1002/jcc.540100208

[38] J. J. P. Stewart, Optimization of parameters for semiempirical methods II. Application, $J$. Comput. Chem. 10 (1989), 221-264. https://doi.org/10.1002/jcc.540100209

[39] A. R. Leach, Molecular Modeling, Essex: Longman, 1997.

[40] P. Fletcher, Practical Methods of Optimization, New York: Wiley, 1990.

[41] W. Kohn and L. Sham, Self-consistent equations including exchange and correlation effects, Phys. Rev. 140 (1965), A1133-A1138. https://doi.org/10.1103/PhysRev.140.A1133

[42] R. G. Parr and W. Yang, Density Functional Theory of Atoms and Molecules, London: Oxford University Press, 1989.

[43] A. D. Becke, Density-functional exchange-energy approximation with correct asymptotic behavior, Phys. Rev. A 38 (1988), 3098-3100. https://doi.org/10.1103/PhysRevA.38.3098

[44] S. H. Vosko, L. Wilk and M. Nusair, Accurate spin-dependent electron liquid correlation 
energies for local spin density calculations: a critical analysis, Can. J. Phys. 58 (1980), 1200-1211. https://doi.org/10.1139/p80-159

[45] C. Lee, W. Yang and R. G. Parr, Development of the Colle-Salvetti correlation-energy formula into a functional of the electron density, Phys. Rev. B 37 (1988), 785-789. https://doi.org/10.1103/PhysRevB.37.785

[46] SPARTAN 06, Wavefunction Inc., Irvine CA, USA, 2006.

[47] P. J. Durant and B. Durant, Introduction to Advanced Inorganic Chemistry, London: Longman, 1972.

[48] M. M. Kuklja and S. N. Rashkeev, Shear-strain-induced structural and electronic modifications of the molecular crystal 1,1-diamino-2,2-dinitroethylene: Slip-plane flow and band gap relaxation, Phys. Rev. B 75 (2007), 104111.

https://doi.org/10.1103/PhysRevB.75.104111

[49] P. Politzer, M. Concha, M. Grice, J. Murray and P. Lane, Computational investigation of the structures and relative stabilities of amino/nitro derivatives of ethylene, J. Mol. Struct. (Theochem) 452 (1998), 75-83. https://doi.org/10.1016/S0166-1280(98)00136-5 